\title{
Type IV melanosomes of the human albino iris
}

\author{
ALISON C E McCARTNEY,' D J SPALTON, ${ }^{2}$ AND T B BULL' \\ From the 'Departments of Histopathology, Charing Cross Hospital Medical School, and ${ }^{2}$ Ophthalmology, \\ St Thomas's Hospital, London
}

SUMMARY Electron microscopy of an iris biopsy specimen from a clinically tyrosinase-negative human albino demonstrated type IV mature melanosomes. Possible mechanisms for the formation in this condition of these organelles, which have not previously been described at this site, are discussed.

Melanosomes, the pigment-bearing organelles of melanocytes, have been classified into four categories. ' 2 The first two categories, types I and II, represent the premelanosomes, which are shuttleshaped organelles formed in the endoplasmic reticulum, and types III and IV, in which there is progressive obliteration of the shuttle-shaped organelles into homogeneous, spherical, membranebound organelles filled with melanin. This is thought to be due to catalysis of tyrosine into dopamine by tryosinase. Albinos of the tyrosinase-negative oculocutaneous type (TNOCA) ${ }^{3}$ were thought not to have organelles of the mature type IV variety on previous studies of the skin, hair bulb, and eyes. ${ }^{4}$

Correspondence to Dr A C E McCartney, Department of Histopathology and Experimental Pathology, Charing Cross Hospital Medical School, Fulham Palace Road, London W6 8RF.
In the normal eye three types of melanin-containing cells are seen in the iris: the stromal melanocyte, derived from neural crest; the pigment epithelial cell, of neuroectodermal origin; and the phagocytic clump cell of Koganei. ${ }^{5}$ A previous light microscopic study of the eyes of a TNOCA patient ${ }^{6}$ failed to show iris stromal melanocytes; the authors did not examine pigmented epithelial cells of the iris by electron microscopy. In our case all three types of iris melanin-containing cells were seen, a finding which has not previously been reported.

\section{Patients, materials, and methods}

An iris biopsy was performed during routine cataract surgery and intraocular lens implantation on the right eye of a 62-year-old woman who was clinically a classical case of TNOCA.

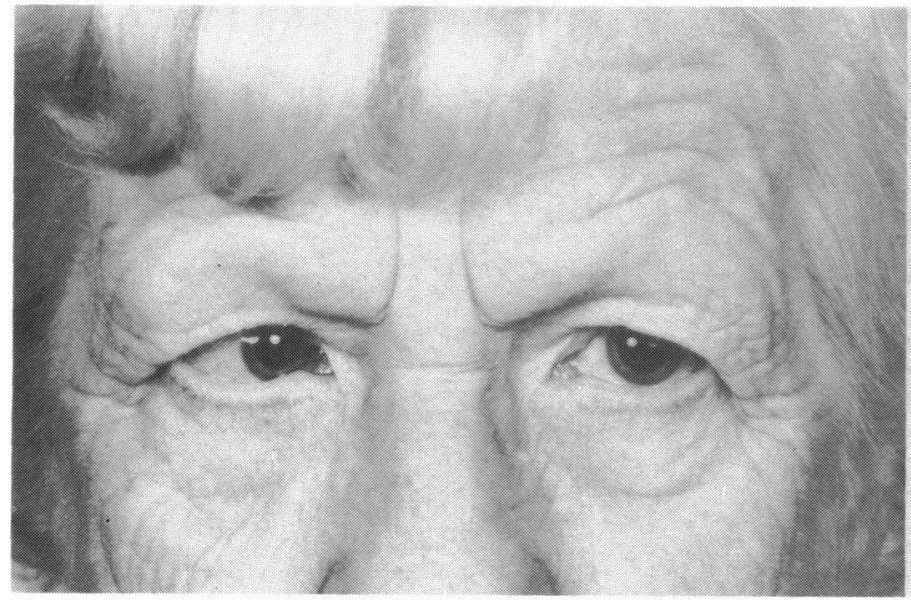

Fig. 1A

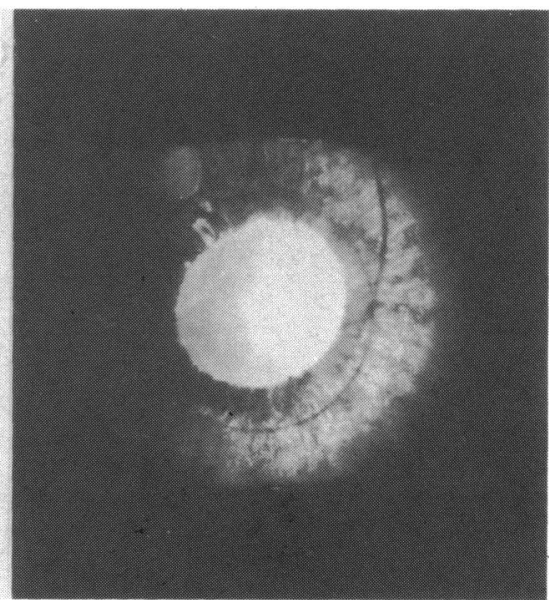

Fig. 1B

Fig. 1A Face of the patient. Notice white hair, eyelashes, and eyebrows, and a right convergent squint.

Fig. 1B Postoperative photograph of the right iris shows gross transillumination against the red reflex. The peripheral iridectomy can be seen superiorly and a Sinsky intraocular lens implant is seen outlined against the red reflex. 
She had had white hair all her life with a pale skin and no freckles or naevi. Her irides were pale grey with marked transillumination (Fig. 1). She was mildly photophobic, with congenital nystagmus, a convergent squint, and visual acuities of counting fingers in the right eye and 6/60 in the left eye. She had a senile cataract in the right eye and typical albinoid fundi. The iris tissue taken from the peripheral iridectomy at surgery was placed in cold Karnovsky (buffered glutaraldehyde and paraformaldehyde) fixative and allowed to reach room temperature. The biopsy specimen was processed and examined in an electron microscope. The melanocytes were photographed and the cell areas and the numbers and areas of melanosomes measured by means of computerised image analysis.

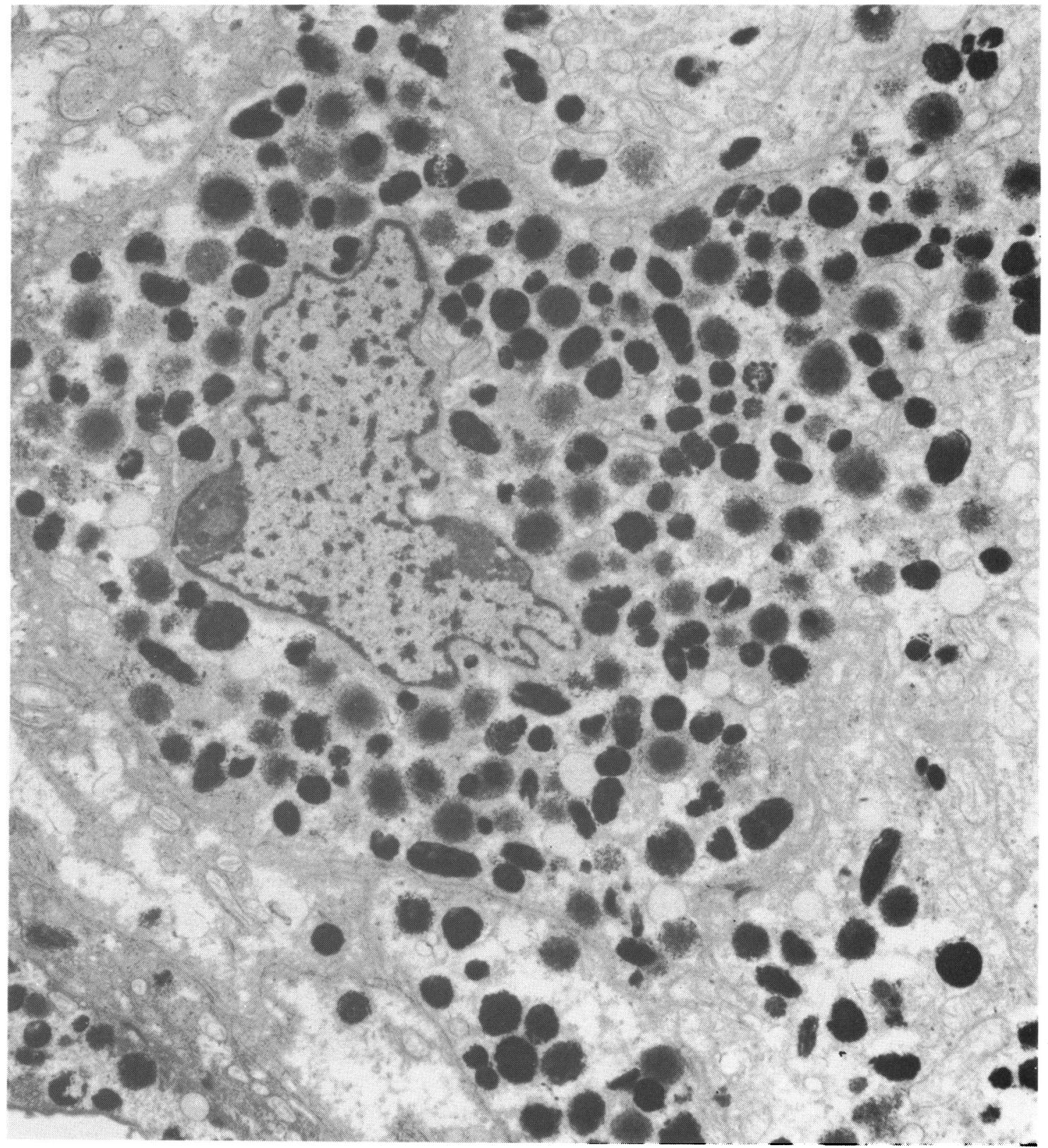

Fig. 2 Pigment epithelial cells of TNOCA iris containing large numbers of type IV and III mature melanosomes. $(\times 20000)$. 


\section{Results}

All three type of melanin-containing cells could easily be identified in this biopsy. There were stromal melanocytes containing small but normally formed mature melanosomes of the type IV variety as well as premelansomes. There was also a layer of pigment epithelial cells containing larger melanosomes of all types, including types III and IV (Figs. 2 and 3). Phagocytic clump cells of Koganei were identified by the presence of larger groups of melanotic particles, not individually membrane bound, contained within lysosomal structures containing large lipid droplets (Fig. 4).
The high statistical significances reached in the following data and tests must be viewed in the light that only a single case was available for study.

The number of stromal melanocytes in the albino patient was not significantly reduced when compared with those in the control population, 54 cells in 6 grid squares compared with a mean of 69 cells in 9 grid squares in the controls. The area of the melanocyte cytoplasm was also not significantly smaller, though very large cells were not seen in the albino and were in the controls. The mean melanocyte cytoplasmic area of the controls was $61 \mu \mathrm{m}^{2}$ (SE $\left.18 \mu \mathrm{m}^{2}\right)$ compared with $19.86 \mu \mathrm{m}^{2}$ in the albino patient, but many of the control melanocytes were also small, one

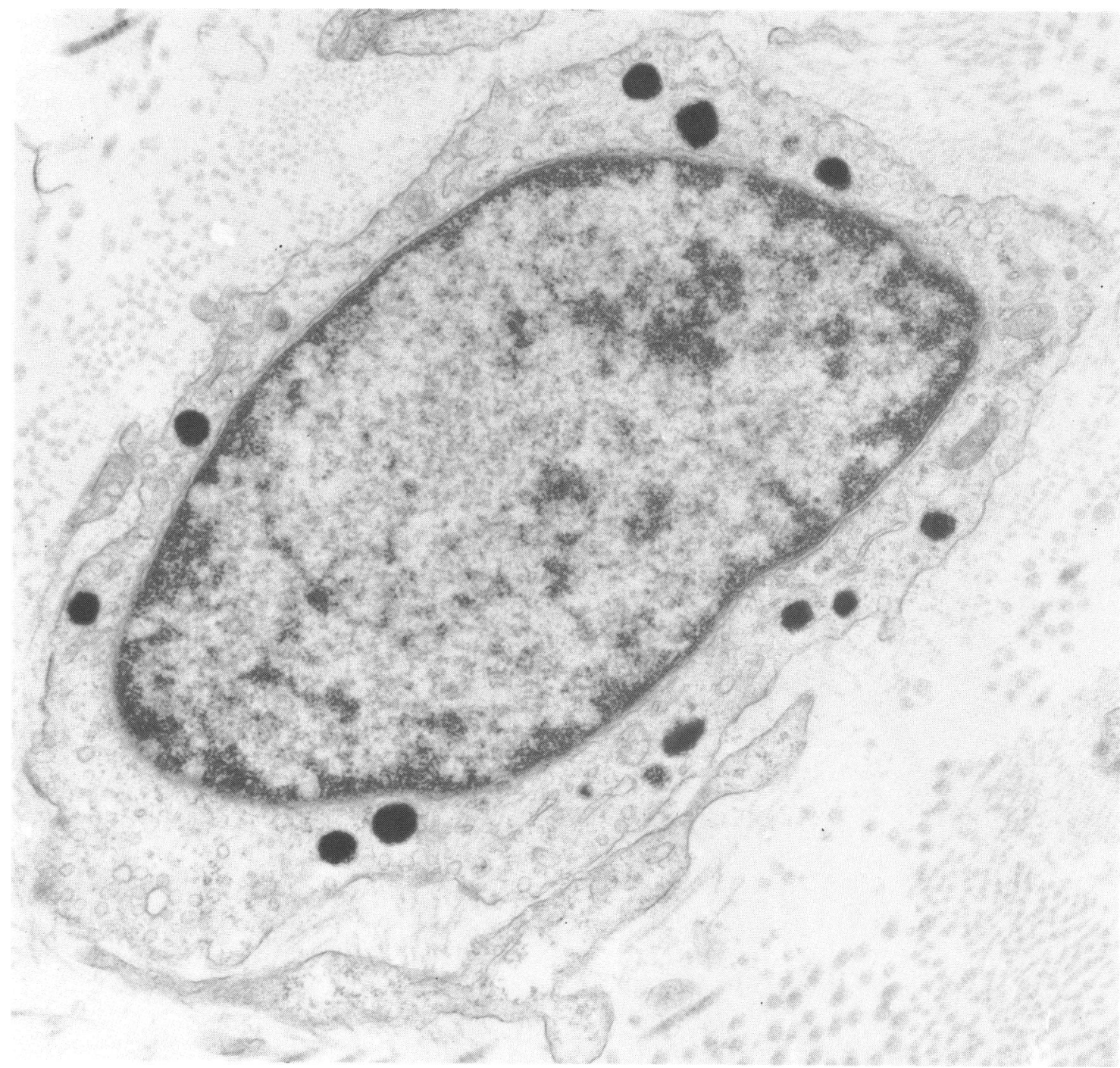

Fig. 3 Stromal melanocytes in TNOCA iris containing mature type IV membrane bound melanosomes. $(\times 20000)$. 
control having a mean melanocyte cytoplasmic area of $27 \mu \mathrm{m}^{2}$ (this patient had blue eyes).

The number of melanosomes within control stromal melanocytes was not significantly greater (53.77, SE 11.2) than in the albino (23.3, SE 5.76).

However, there were markedly more type II melanosomes within the albino stromal melanocytes, where $19 \%$ were type II, $61 \%$ type III, and only $20 \%$ type IV, whereas the controls had $<1 \%$ type II (premelanosomes), 29\% type III, and 70\% type IV. $10 \%$ of pigment epithelial melanosomes were type II compared with less than $2 \%$ in controls.

Type II melanosomes were difficult to see in control patients. When melanosomal areas were calculated, only type III and type IV melanosomes were measured in the albino. Measurements were made of 3305 control stromal melanosomes and 291 albino type III and IV melanosomes. The mean stromal melanosomal area was significantly reduced in the albino $\left(0.0263 \mu \mathrm{m}^{2}, \mathrm{SD} 0.0101\right)$ compared with the controls $(0.0438$, SD 0.0061) $(p<0.001)$.

A similar significant difference was seen in the size of the type III and IV melanosomes of the pigment epithelial melanocytes. 1522 control pigment epithelial melanocytes were measured and compared with 269 type III and type IV melanosomes in the pigment epithelial cells of the albino. The mean area of the control patients' melanosomes was $0.397 \mu \mathrm{m}^{2}$ (SD 0.059) compared with $0.141 \mu \mathrm{m}^{2}$ (SD 0.066) in the albino $(\mathrm{p}<0 \cdot 001)$.

\section{Discussion}

The presence of mature forms of melansomes especially in stromal cells in this biopsy specimen came as a surprise, even though Fitzpatrick and Queredo ${ }^{2}$ had predicted that they might occur. Fulton et al. ${ }^{6}$ showed retinal pigment epithelial melanosomes and desc-

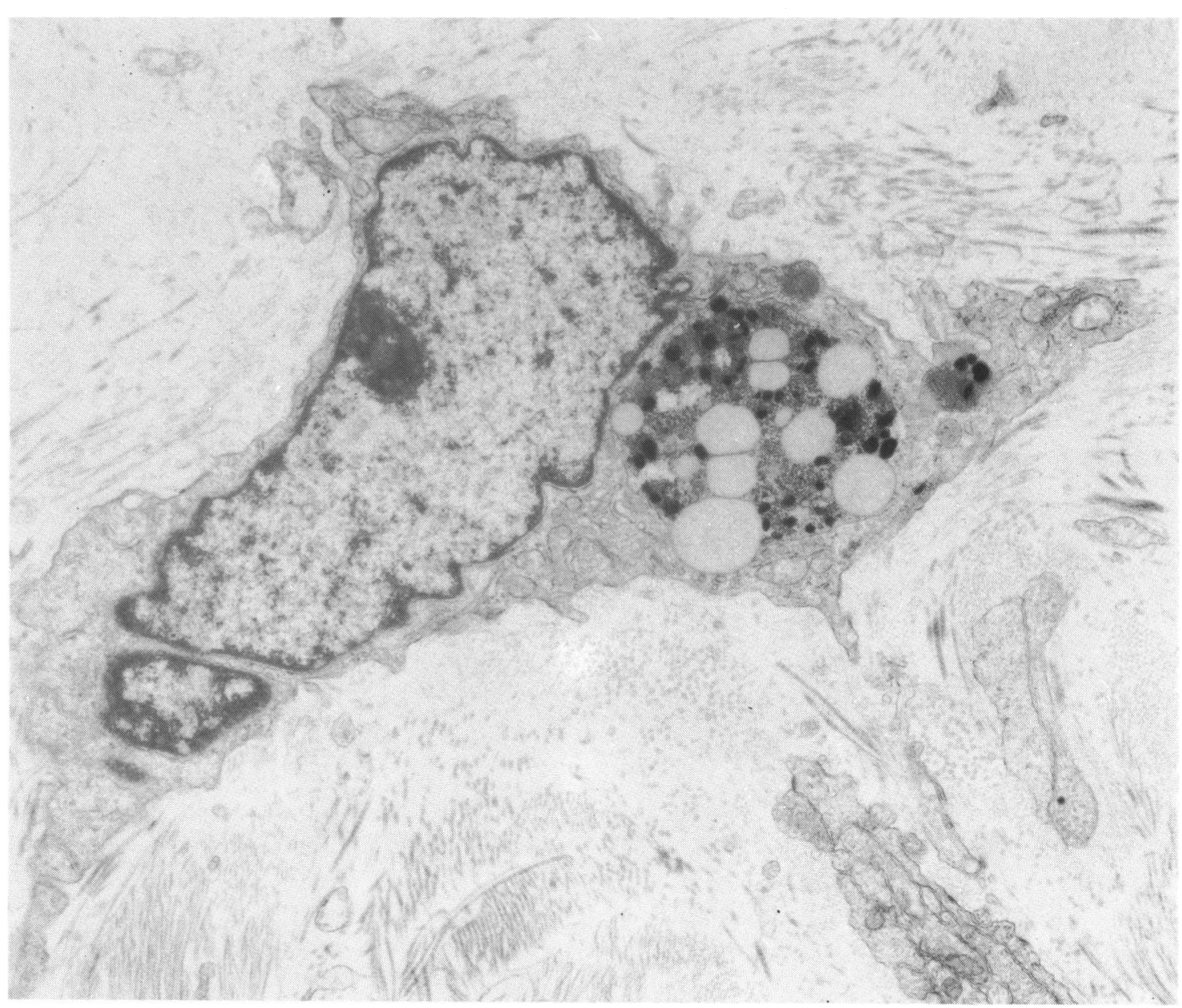

Fig. 4 Phagocytic clump cell of Koganei containing melanin fragments within lysosome with lipid droplets. $(\times 13500)$. 
ribed the iris epithelium as pigmented, but they failed to show the stromal melanocyte at light microscopic level, and it had not been anticipated that they could be easily seen at electron microscopy. Animal studies may have been misleading, since animals do not have the greyish irises seen in human albinos, even of the TNOCA variety. The marked transillumination of the albino patient's iris (Fig. 1B) arises presumably both as a result of increasing numbers of premelanosomes, compared with controls, and the smaller size of the type III and IV melanosomes in melanocytes of both stroma and pigment epithelium.

From this biopsy specimen it appears that melanin can be laid down in organelles normally, in the presumed absence of the catalyst tyrosinase, though fewer melanosomes are fully pigmented. Although a recent paper ${ }^{7}$ has suggested that a negative hair bulb or tyrosinase assay in TNOCA may be a result of insensitive assays or the presence of inhibitors, and has described tanning in a patient with TNOCA, it is possible that melanin formation can occur in the absence of the specific enzyme tyrosinase by two alternative pathways. One way is to use another enzyme catalyst such as endogenous peroxidase found in many cells, including mast cells, ${ }^{8}$ which are also present in the iris stroma. ${ }^{9}$ These enzymes can act independently of tyrosinase and have been shown to be present histochemically at many sites. An alternative and simpler mechanism can also be postulated.

If tyrosinase is acting as a catalyst, then theoretically the conversion of tyrosine to dopamine should occur slowly by itself in the absence of the catalyst. The slowness of this reaction may explain why no mature melanin was seen within the iris stromal cells of the albino child previously described, ${ }^{6}$ who was only 13 , whereas our patient was 62 . The formation of the phagocytic clump cells of Koganei implies that the melanin-containing cells are also being broken down over a period of time.

\section{References}

1 Seiji M, Fitzpatrick TB, Birbeck MSC. The melanosome: a distinctive subcellular particle of mammalian melanocytes and the site of melanogenesis. J Invest Dermatol 1961; 36: 243-52.

2 Fitzpatrick TB, Queredo WC Jr. Albinism. In: Stanbury JB, Wyngaarden JB, Fredrickson DS, eds. The metabolic basis of inherited disease. New York: McGraw-Hill, 1972: 326-36.

3 Witkop CJ Jr, White JG, Nance WE, Jackson CE, Desnick S. Classification of albinism in man, in skin, hair and nails. In: Bersgma D, ed. Birth Defects 1971; 7: 13-25.

4 Klintworth G. Disorders of phenylalanine and tyrosine metabolism. In: Klintworth G, Garner A, eds. The pathobiology of ocular disease. New York, Basel: Dekker, 1982: 948-54.

5 Fine BS, Yanoff M. The uveal tract. In: Ocular histology, a text and atlas. 2nd edn. Hagerstown: Harper and Row, 1979: 197-247.

6 Fulton AB, Albert DM, Craft JL. Human albinism: light and electron microscopic study. Arch Ophthalmol 1978; 96: 305-10.

7 Van Dorp DB, Van Haeringen NJ, Glasuis E. Evaluation of hair bulb incubation test and tyrosinase assay in the classification of albinism. Ophthalmic pediatr Genet 1982; 1: 189-200.

8 Okun M, Edelstein L, Or N, Hamada G, Donnellan B. The role of peroxidase vs. the role of tyrosinase in enzymatic conversion of tyrosine to melanin in melanocytes, mast cells and eosinophils; an autoradiographic-histochemical study. J Invest Dermatol 1970; 55: 1-12.

9 Fine BS, Yanoff M. Arrangement of tissues and cells. In: Ocular histology, a text and atlas. 2nd edn. Hagerstown: Harper and Row, 1979: 53-7. 